\title{
Pro-gastrin-releasing peptide (ProGRP) as a biomarker in small-cell lung cancer diagnosis, monitoring and evaluation of treatment response
}

This article was published in the following Dove Press journal:

Lung Cancer:Targets and Therapy

Number of times this article has been viewed

\section{Ewa Wojcik \\ Jan Kanty Kulpa}

Department of Clinical Biochemistry, Maria Skłodowska-Curie Memorial

Cancer Center and Institute of

Oncology, Cracow, Poland
Correspondence: Jan Kanty Kulpa Department of Clinical Biochemistry, Maria Skłodowska-Curie Memorial Cancer Center and Institute of Oncology, 3I-II 5 Cracow, Garncarska II, Poland $\mathrm{Tel}+48$ I2 6348484

Mob +48 501530087

Email z5jkulpa@cyfronet.pl

\begin{abstract}
Lung cancer belongs to malignant tumors that possess the highest rates of morbidity and mortality in the world. A number of morphological, biological and clinical features justify the distinction of small-cell carcinoma with respect to the other histological types of lung cancer. The predominant neuroendocrine phenotype is critical for the selection of biomarkers used in diagnostics, monitoring and evaluation of treatment response; early onset relapses in patients with small-cell lung cancer (SCLC) and the evaluation of their prognosis. Although for a long time the neuron-specific enolase (NSE) was considered to be the marker of choice for this tumor, it is now increasingly important to pay attention to concentrations of pro-gastrinreleasing peptide (ProGRP). The results of this marker have been implicated in the differential diagnosis of non-small lung cancer and SCLC, chemotherapy and radiotherapy monitoring as well as evaluation of treatment response. The subject of this series of studies is to determine the usefulness of ProGRP in the evaluation of patients' prognosis and its predictive value. The current aim for the optimization of the effectiveness of biochemical diagnostics of SCLC is recommended by complementary ProGRP and NSE studies. The present work is a summary of the latest reports regarding diagnostic utility of these markers in SCLC.
\end{abstract}

Keywords: small-cell lung cancer, tumor markers, predictive and prognostic values

\section{Introduction}

Lung cancer is one of the most common malignant neoplasms in the world and for a number of years has presented a tendency to growth in both the number of new cases and the number of deaths. It is estimated that in 2002, the number of new cases and deaths due to lung cancer was 1,352 million and 1,178 million, respectively, whereas in 2012, 1,825 million new cases and 1,590 million deaths were reported. ${ }^{1,2}$ The principal risk factor for lung cancer is the carcinogenic effects of tobacco smoke, also to some extent physical and chemical environmental factors, as well as genetic factors, particularly those related to the polymorphism of the genes involved in the chemical metabolism of carcinogenic tobacco smoke. ${ }^{3}$

There are two major types of lung cancer. Adenocarcinoma (40\%), squamous cell carcinoma $(30 \%)$ and large cell carcinoma (10\%) are histological subtypes of non-small-cell lung cancer (NSCLC). However, due to the different morphological, biological and clinical characteristics of small-cell lung cancer (SCLC; 13-20\%), it is treated as a separate disease. ${ }^{4}$ This tumor is characterized by high aggressiveness and an increased tendency to create metastasis. At the moment of diagnosis, only $\sim 30 \%$ of patients have limited stage of disease (limited disease [LD] stage by Veterans 
Administration Lung Study Group [VALCSG] classification). ${ }^{5}$ Although it emphasizes the significant chemo- and radiosensitivity SCLC, in a relatively short period of time a proportion of patients develop resistance to treatment, leading to the spread of the disease. ${ }^{4,6}$

SCLC is a tumor consisting of small cells with scant cytoplasm and indistinct cell borders, finely grained nuclear chromatin and absent or inconspicuous nucleoli, and is characterized by high mitotic ratios. ${ }^{7}$ The dominant feature of small-cell cancer cells is their neuroendocrine (NE) phenotype, associated with possessing the properties of the amine precursors uptake and decarboxylation (APUD) system. Small-cell cancer cells are characterized by their ability to capture and decarboxylate catecholamine and its precursors, which promote the synthesis of antiduretic hormone and adrenocorticotropic hormone, and are associated with increased expression of a number of neuropeptides that include calcitonin, chromogranin A ( $\mathrm{CgA})$, synaptophysin, neuron-specific enolase (NSE), gastrin-releasing peptide (GRP) and also insulin-like growth factor $1 .{ }^{8}$

For this reason, the study of selected neuropeptides is used in the diagnosis of lung cancer alongside other cancer markers. Although tumor markers are not generally used for the detection of lung cancer in asymptomatic patients, NE markers provide important information for differential diagnosis of tumor types, prognosis of SCLC, treatment monitoring and early detection of disease recurrence. ${ }^{9}$

\section{Serum biomarkers in lung cancer diagnostics CgA}

$\mathrm{CgA}$, next to chromogranin B and secretogranin II, belongs to the family of granin, acid glycoproteins, present in the secretory granules of most normal and neoplastic NE cells - and is considered to be the main nonspecific marker of neuroendocrine tumors (NETs). ${ }^{10}$ Elevated CgA levels are found in a significant percentage of patients with NE gastrointestinal-pancreatic tumors, neuroblastomas and bronchopulmonary NETs and also in patients with medullary thyroid carcinoma or prostate cancer. Data on sensitivity and diagnostic specificity of $\mathrm{CgA}$ show considerable variation (10-100\% and $68-100 \%$, respectively) depending on the location of lesion, stage of the disease, degree of histological malignancy and performance status (PS). Particularly, high concentrations of $\mathrm{CgA}$ and frequency of elevated markers are found in neuroendocrine gastrointestinal pancreatic tumors (GEP-NET) and carcinoid tumors. In SCLC, the sensitivity and diagnostic specificity of $\mathrm{CgA}$ concentrations are slightly lower than in NSE or pro-gastrin-releasing peptide (ProGRP). ${ }^{11,12}$ Limitations in the usefulness of $\mathrm{CgA}$ tests are due to technical difficulties, including various antibodies used in reagent kits, lack of a universal standard and different accepted cutoff values. ${ }^{13}$

\section{NSE}

For a long time, an NSE, being an enolase isoenzyme, built from a homodimer consisting of two gamma subunits $(\gamma \gamma)$, the presence of which has been shown in nerve and NE cells, was considered as a marker of choice in the diagnosis of SCLC. The organ localization of NSE causes the elevated levels of the marker to be found in various lesions of nerve tissue such as areas of ischemic stroke, intracerebral hemorrhage or post-traumatic brain injury. NSE is recognized as a marker of various cancers of the nervous and NE tissues such as malignant melanoma, seminoma, renal cancer, carcinoid, germinoma, immature teratoma, medullary thyroid carcinoma and SCLC. ${ }^{14}$ The first NSE study relating to SCLC was presented by Carney et al, ${ }^{15}$ in 1982, showing a strong correlation between the percentage of elevated NSE and the stage of the disease as well as exposing the usefulness of marker in the assessment of chemotherapy response. The results of NSE determinations in patients with SCLC and NSCLC, benign lesions in the lung and other respiratory diseases, as well as in healthy individuals, are the subject of numerous studies and meta-analysis. ${ }^{16-18}$ At the cutoff values between 10 and $25 \mu \mathrm{g} / \mathrm{L}$, the diagnostic sensitivity and specificity of NSE vary between $43.8 \%$ and $70 \%$ and $84.7 \%$ and $93.8 \%$, respectively. ${ }^{18}$

A number of studies have examined the relationship between the concentration of the marker and various clinical parameters (e.g., stage of disease, PS, degree of histological malignancy), the usability of the marker in the monitoring of treatment and its predictive and prognostic value. ${ }^{19}$ These works are supplemented by publications on various methodological aspects: differences in the type of antibodies used (their ability to react only with the homodimer $\gamma \gamma$ enolase and with the heterodimer $\alpha \gamma$ ) and the resulting differences in the cutoff values that had a significant impact on the diagnostic usability of the test results. ${ }^{20,21}$

\section{Pro-GRP}

The production and release of the gastrin and the GRP into the circulation remains in close relation to the properties of the APUD system. This neuropeptide, which for the first time was isolated from gastric nerve fibers by McDonald et $\mathrm{al}^{22}$ in 1978, is made up of 27 amino acid residues and has a characteristic 
decapeptide that has a significant homology with the bombe$\sin$ in the amino acid sequence in the C-terminal fragment. Expression of GRP outside the gastrointestinal tract has been demonstrated, for example, in NE cells of the lungs of the fetus, nervous system cells, normal bronchial epithelial cells, pulmonary fibroblasts and adult NE cells. ${ }^{23-25}$ GRP was expressed in tumor cells at different organ locations, among others: in $62 \%$ of colon cancer patients, $59 \%$ of patients with pancreatic adenocarcinoma, $60 \%$ of patients with prostate cancer, $39 \%$ of patients with breast cancer, $74 \%$ of SCLC patients and $42 \%$ of lung carcinoid patients. ${ }^{26,27}$

Plasma GRP levels in healthy subjects range from 100 to $542 \mathrm{ng} / \mathrm{L}$, while in patients with SCLC with cerebral metastases, six times higher levels of GRP are observed. ${ }^{28}$ Studies using a GRP radiotracer ( ${ }^{99} \mathrm{TC}-\mathrm{RP} 527$ ) showed high isotope activity in the urinary bladder, liver, gall bladder wall and intestines of healthy subjects, indicating that both kidneys and liver are the main excretory sites of this peptide. Owing to the short duration of the half-life of the marker in the circulation, lasting only 1.5 minutes, the determinations of GRP levels in serum did not find any use in diagnostics. ${ }^{29}$ Like most peptide hormones, GRP is synthesized in the form of a biologically inactive prohormone (precursor). A number of enzymes are involved in the conversion of proGRP to GRP: trypsin-like prohormone convertase (PC1 and PC2), carboxypeptidase $\beta$-like peptidyl and alpha-amidation peptidylglycine monooxygenases. In 1988, during immunohistochemistry studies, Cuttitta et $\mathrm{al}^{30}$ confirmed the presence of GRP and its peptide precursor in SCLC cell lines and cells, and isolated three biologically inactive gastrin-releasing propeptide forms that were constructed from single polypeptide chains, containing 125 , 118 or 115 amino acid residues. In molecules of these isoforms, the identical element is composed of 27 amino acid residues, the GRP the three amino acid (Gly-Lys-Lys) center, where the precursor peptide chain breaks down, and the fixed fragment located between 31 and 98 amino acids of the propeptide, while the isoforms differ in C-terminal chains containing 17, 20 or 27 amino acids. ${ }^{31}$ Miyake et al ${ }^{32}$ demonstrated that SCLC cells produce equimolar amounts of GRP (1-27) and ProGRP chain fragment (31-98), proving them to be products of the same gene. While originally thought to only be GRP (1-27) biological activity and its C-terminal GRP fragment (17-27), studies by Patel et $\mathrm{al}^{33}$ confirmed the biological activity of $\mathrm{C}$-terminal propeptide fragments, localized between 42 and 79 as well as 80 and 98 amino acids. Using the recombinant human ProGRP fragment (31-98), two monoclonal antibodies for the heavy chain $\gamma 1$ (2B10 and 3G2), reacting with two epitopes on this fixed fragment, were developed. This has opened the door to the development of ProGRP reagent kits by ELISA. ${ }^{31}$ At present, there are essentially three techniques for measuring ProGRP in serum: time resolved immunofluorometric assay (TF-IFMA) using AutoDELFIA instrument, chemiluminescence assay (CMIA) using Architect analyzer and electrochemiluminescence assay (ECLIA) using cobas analyzer.

ProGRP (31-98) concentration in the samples of cord blood serum and the neonate is approximately ten times higher than in adults. Within 2 years after birth, ProGRP levels were dropping rapidly and then gradually decreased during childhood to the upper limit of normal levels in adults, which is generally $<60 \mathrm{ng} / \mathrm{L} \cdot{ }^{34-37}$ High levels of ProGRP during fetal life, as well as its gradual decline, are considered as confirmation of the role of GRP in stimulating cell growth. ${ }^{38}$ In healthy adult subjects, there is a tendency for ProGRP levels to increase with age, showing a slightly higher concentration in women compared to men, higher concentrations in tobacco smokers and higher concentrations in individuals with a higher body weight. ${ }^{39}$ Owing to the fact that ProGRP is primarily metabolized by the kidneys, especially in chronic renal failure, higher serum ProGRP levels are observed. Hence, it is recommended to perform creatinine determinations concurrently with ProGRP. ${ }^{35}$ While the majority of patients with SCLC show elevated and often very high levels of ProGRP, only 7-13\% of non-small-cell cancers are present, mainly in advanced stages of the disease. Moderately elevated ProGRP levels, i.e., not $>80 \mathrm{ng} / \mathrm{L}$, are observed in $\sim 2-4.1 \%$ of patients with gastrointestinal disorders, acute hepatitis and noninfectious inflammatory conditions of the lungs. Elevated ProGRP levels are found in a certain percentage of patients with localized cancer other than that of the lung $(13 \%)$. While liver cancer and adenocarcinoma of the pancreas have not shown elevated concentrations of this marker, they are found in 3\% of breast cancer patients, $7 \%$ of gynecological cancer patients, $27 \%$ of leukemia patients and $>40 \%$ of NET cases. ${ }^{35,40-42}$ The subject of the study is also related to issues of the effects on the results of determination of the marker concentration of biological material (plasma vs. serum), as well as various physicochemical factors. ${ }^{36,43-45}$

\section{ProGRP as a diagnostic biomarker}

The first attempts to verify the usefulness of ProGRP in lung cancer patients were conducted in 1994 by Miyake et al and in 1996 by Takada et al. Their studies have shown a high diagnostic sensitivity of marker in SCLC, to the amount of $67-73 \%$ in patients with LD and $79-80 \%$ in patients with extensive disease, while in patients with squamous cell lung carcinoma and adenocarcinoma, the diagnostic 
sensitivity of ProGRP was the lowest, ranging between 3\% and $14 \% .^{32,46,47}$ Despite the encouraging preliminary results to be found in the recommendations of the 1999 European Group on Tumor Markers (EGTM), the use of NSE in lung cancer diagnosis was preferred because high concentrations of this marker are associated with a greater probability of SCLC detection. ${ }^{48}$ According to expert opinion, the NSE level should be assessed before, during and after treatment in patients suffering from this cancer in order to detect an early relapse. Changes in NSE levels during therapy have been found to be helpful in evaluating patients' response to treatment. In all patients with complete remission, the initial drop in elevation to normal values was observed after the first series of chemotherapy. ${ }^{49-51}$ Numerous studies also confirm the adverse effects of initially high concentrations of NSE on the patients' survival. ${ }^{52-55}$

Research into the usefulness of ProGRP, conducted at various centers around the world, has focused on the evaluation of marker concentration in relation to a number of clinical parameters, including stage of disease, tumor type, PS and presence of distant metastases. The subject of a series of studies is an analysis of the relationship between ProGRP and NSE levels, as well as other tumor markers, in the respect of optimizing the diagnosis of lung cancer patients.

If the studies of Stieber et $\mathrm{al}^{47}$ indicated comparable diagnostic sensitivity of both markers ( $47 \%$ vs. $45 \%$ ) at fixed $95 \%$ diagnostics specificity, the studies from other centers documented a higher diagnostic sensitivity of ProGRP compared to NSE in SCLC patients: $62.4 \%$ vs. $33.3 \%$ in the study by Takada et al ${ }^{46} 86 \%$ vs. $53 \%$ in the study by Niho et al; ${ }^{55} 80 \%$ vs. $75 \%$ in the study by Lamy et $\mathrm{al}^{11}$ and $78.4 \%$ vs. $48.6 \%$ in the study by Nisman et al. ${ }^{56}$ More accurate analysis of the usefulness of tumor markers in patients with lung cancer was carried out in the following years by Molina et al. ${ }^{17}$ In all, 155 patients with benign lung diseases, 472 with NSCLC and 175 with SCLC were studied. ProGRP concentrations $>50 \mathrm{pg} / \mathrm{mL}$ were found in $76.6 \%$ of SCLC patients, $15.7 \%$ of NSCLC patients and $3.8 \%$ of those with non-infectious diseases and $2 \%$ of those with infections, while NSE levels $>25 \mathrm{ng} / \mathrm{mL}$ were $65.1 \%, 10.4 \%, 2.0 \%$ and $0 \%$, respectively. The results of tumor markers in lung cancer patients may be helpful in assessing the probability of occurrence of a particular type of histological tumor occurring. In the available literature, we find two diagnostic algorithms with related content whose authors are Molina et a $1^{17}$ and Liu et al..$^{57}$ In our work, we presented an algorithm developed by Liu et al (Table 1).

For NSE cutoff values 30, 35 and $45 \mu \mathrm{g} / \mathrm{L}$, the probability of SCLC is $81.7 \%, 95.8 \%$ and $97.4 \%$, respectively, while for ProGRP cutoff values 100, 150 and $300 \mathrm{ng} / \mathrm{L}$, the probability of SCLC is $86.3 \%, 93.7 \%$ and $98.9 \%$, respectively. According to Molina et al, ${ }^{17}$ a high ProGRP level may confirm the presence of small-cell lung carcinoma. Similar results, but only for ProGRP, were obtained at Qingdao Hospital in China, however, with a completely different proportion of NSCLC/ SCLC patients (with 17-fold more NSCLC). ${ }^{57}$ Analysis of the area under the receiver operating characteristic (ROC) curves (AUCs) has confirmed the greater usability of ProGRP than NSE in differential diagnostics of SCLC and NSCLC. The area under the ROC curve for ProGRP was 0.945 and was significantly higher compared to 0.764 - the AUC for NSE. ${ }^{57}$ The optimal cutoff point for ProGRP with the aim of differentiation of SCLC and NSCLC established by Nisman et $\mathrm{al}{ }^{58}$ was $140 \mathrm{ng} / \mathrm{L}$. The diagnostic sensitivity of ProGRP, at this cutoff, in patients with pure SCLC, amounted to $84 \%$ and was higher than that in the group containing also 5\% patients with mixed tumors SCLC-NSCLC (70\%). In these studies, similar diagnostic utility of ProGRP was demonstrated for tumors with NE features. The rates of elevated levels of ProGRP levels in patients with NSCLC classified as large-cell NE carcinoma (LCNEC) and non-small-cell lung cancer with NE differentiation (NSCLC-NED) were 36.4\% and $28.6 \%$, respectively. ${ }^{58}$

Considering the fact that one of the main activators in the differentiation of lung specific genes is the thyroid transcription factor-1 (TTF-1), the relationship between TTF-1 expression and ProGRP level is analyzed. It has been shown that low concentrations of ProGRP are more frequently associated with lack ofTTF-1 expression. ProGRP concentration

Table I Criteria of lung cancer histological diagnosis

\begin{tabular}{lll}
\hline Histological type & Criteria & Correct classification (\%) \\
\hline NSCLC & $\mathrm{SCC} \geq 2 \mathrm{ng} / \mathrm{mL}$ and ProGRP $<100 \mathrm{pg} / \mathrm{mL}$ & 97.9 \\
& $\mathrm{SCC}<2 \mathrm{ng} / \mathrm{mL}$ and ProGRP $<100 \mathrm{pg} / \mathrm{mL}$ and CYFRA $21-\mathrm{I}>3.3 \mathrm{ng} / \mathrm{mL}$ & 92.8 \\
& $\mathrm{SCC}<2 \mathrm{ng} / \mathrm{mL}$ and ProGRP $<100 \mathrm{pg} / \mathrm{mL}$ and CEA $>5 \mathrm{ng} / \mathrm{mL}$ & 95.3 \\
$\mathrm{SCLC}$ & $\mathrm{SCC}<2 \mathrm{ng} / \mathrm{mL}$ and ProGRP $\geq 100 \mathrm{pg} / \mathrm{mL}$ and NSE $\geq 35 \mathrm{ng} / \mathrm{mL}$ & 91.4 \\
& $\mathrm{SCC}<2 \mathrm{ng} / \mathrm{mL}$ and ProGRP $>150 \mathrm{pg} / \mathrm{mL}$ & 90.5 \\
$\mathrm{AD}$ & $\mathrm{SCC}<2 \mathrm{ng} / \mathrm{mL}$ and ProGRP $<100 \mathrm{pg} / \mathrm{mL}$ and CEA $>5 \mathrm{ng} / \mathrm{mL}$ & 85.8 \\
$\mathrm{SQC}$ & $\mathrm{SCC} \geq 2 \mathrm{ng} / \mathrm{mL}$ and ProGRP $<100 \mathrm{pg} / \mathrm{mL}$ and CA I $25<100 \mathrm{U} / \mathrm{mL}$ and CYFRA $2 \mathrm{I}-\mathrm{I} \geq 3.3 \mathrm{ng} / \mathrm{mL}$ & 79.5 \\
\hline
\end{tabular}

Note: Adapted from Liu L, Teng J, Zhang L, et al. The combination of the tumor markers suggests the histological diagnosis of lung cancer. Biomed Res Int. 2017;2017:9.56 Abbreviations: NSCLC, non-small-cell lung cancer; SCLC, small-cell lung cancer; AD, adenocarcinoma; SQC, squamous carcinoma. 
$<140 \mathrm{ng} / \mathrm{L}$ was observed in $53.9 \%$ patients with no TTF-1 expression and only in $8.8 \%$ of patients with expression of this transcription factor. ${ }^{58}$

In the Chinese-developed meta-analysis studies, based on the results of the studies presented in 21 publications, the diagnostic usability of ProGRP in patients with SCLC has been summarized. Diagnostic sensitivity of ProGRP varies within the range of $54-78 \%$ with diagnostic specificity $72-99 \% .^{59-61}$ Furthermore, the confirmation of the usefulness of ProGRP in SCLC diagnosis was the high values of the positive likelihood ratio (PLR; 13.8) and the diagnostics odds ratio (DOR; 53.1)..$^{62,63}$

\section{ProGRP in monitoring and evaluation of treatment response in lung cancer}

A number of studies have evaluated the determination of the usefulness of ProGRP in the patients' response to the therapy. In patients with LD of SCLC undergoing combined chemo- and radiotherapy, analysis of ProGRP levels showed a gradual decline in the level of the marker during treatment, dependent on the initial level of the marker. The assessment of the kinetics of ProGRP concentration changes enabled the determination of the biological half-life of the marker. For ProGRP, it ranges from 19 to 26 days, and for NSE, it ranges from 4.6 to 11 days. ${ }^{64}$ The percentage of elevated ProGRP scores (compared to the cutoff value in healthy individuals and patients with benign lung diseases), not only before the one cycle of chemotherapy but also before each cycle, was significantly higher than the percentage of elevated NSE results. For ProGRP and NSE, the percentage of elevated LD-SCLC that resulted in one cycle was $79.7 \%$ vs. $57.8 \%$; two cycles, $67.2 \%$ vs. $6.3 \%$; three cycles, $43.8 \%$ vs. $0 \%$; four cycles, $27.1 \%$ vs. $1.7 \%$ and before the fifth cycle was $26.9 \%$ vs. $1.9 \% .{ }^{65}$ The reasons for the rapid normalization of NSE levels during treatment are difficult to explain. Perhaps, this phenomenon should be combined with the influence of chemotherapeutics on enolase activity and disorders of anaerobic glycolysis, in which this enzyme participates. Changes in ProGRP concentration appear to be more relevant to assessment of the chemotherapy effects and may indicate inhibition of tumor cell proliferation. Studies carried out by Yonemori et a ${ }^{66}$ demonstrated elevated ProGRP concentrations after induction of chemotherapy in patients with localized SCLC before prophylactic cranial irradiation (PCI), which may suggest the presence of residual disease even though imaging studies have proven a successful treatment (complete remission or partial remission). The usefulness of ProGRP determination in the monitoring of therapy was also confirmed by other researchers in different stages of the disease, in which LD-SCLC patients did not exceed $50 \%$. Prior to each cycle of chemotherapy, ProGRP levels in patients with progression were significantly higher in comparison to the others, and in patients with remission of tumor, the progress was significantly lower compared to those with progression or stabilization. A significant drop in marker concentration between chemotherapy cycles was observed only in patients who responded well to the treatment. ${ }^{58,67,68}$ With radiologic evidences, determination of ProGRP may be helpful in identifying patients who will respond well to therapy at the early treatment phase. ${ }^{67}$ The usefulness of ProGRP in patients with small-cell carcinoma is further demonstrated by the observed relationship between ProGRP mRNA and serum markers, not only before treatment but also during therapy ${ }^{69}$

Chest radiography, computed tomography $(\mathrm{CT})$ of the chest and upper abdomen and magnetic resonance or $\mathrm{CT}$ of the brain performed twice a month for a period of 6 months and then once a quarter for 18 months, with an aim at detecting the relapse after chemotherapy, demonstrated a high degree of compatibility of changes in the ProGRP and NSE levels with radiological results in patients with baseline elevations of both markers. However, in the group of patients with normal levels of markers, changes in their concentration at the time of recurrence were significantly less marked. It should be emphasized that there was no false-positive elevation of tumor markers in patients without disease recurrence. ${ }^{70}$ According to the Recommendations of Evaluation Criteria in Solid Tumors (RECIST), monitoring of the level of markers during treatment may be helpful in assessing complete remission..$^{71}$ This suggestion is confirmed by the results of the study by Yonemori et al. ${ }^{66}$ The ProGRP level before PCI had not only predictive value but also prognostic value. In patients with LD-SCLC, a relationship between ProGRP level before PCI and the occurrence of the brain metastases was confirmed. The risk of isolated cerebral metastases in patients with ProGRP levels $>46 \mathrm{pg} / \mathrm{mL}$ was 12.5 times higher than in patients with normal levels. In the opinion of researchers, patients with complete remission but with elevated ProGRP after four cycles should be given another two following cycles of chemotherapy to normalize the level of the marker and to completely eliminate the remaining tumor cells in order to reduce the risk of the brain recurrence. ${ }^{66}$

Further recommendations regarding the usefulness of marker determinations in lung cancer patients were developed by the National Academy of Clinical Biochemistry (NACB) in 2006. ${ }^{9,72}$ The usefulness of ProGRP determination, in addition to NSE, has also been confirmed in differential diagnosis of lung cancer, in monitoring treatment of SCLC patients with advanced stage of disease and in detecting relapses. 


\section{Prognostic value of ProGRP}

The controversy over the usefulness of ProGRP in SCLC is related to the prognostic value of this marker. Initially, feedback on the usefulness of the marker was negated. ${ }^{5}$ However, the studies were conducted further, taking $50 \mathrm{ng} / \mathrm{L}$ as a value differentiating patients with regard to survival, while $>80 \%$ patients with SCLC before therapy had an elevated level of this marker. ${ }^{54,73}$ The significant effect of ProGRP on survival has first been demonstrated in patients with limited cancers. As demonstrated, the median overall survival of patients with pretreatment ProGRP of $<410 \mathrm{ng} / \mathrm{L}$ was 27 months and that of ProGRP $>410 \mathrm{ng} / \mathrm{L}$ was 18 months. ${ }^{65}$ The higher discriminatory value $(800 \mathrm{ng} / \mathrm{L})$ associated with a significantly worse prognosis was obtained in the group, which also included $66 \%$ of patients in the advanced stage of cancer. ${ }^{56}$ The survival dependence from the initial marker level was also confirmed, using as discriminatory value the optimal ProGRP cutoff (140 ng/L), established during assessment response of SCLC patients to chemotherapy. ${ }^{16}$ It seems that the composition of the study group determines the value of ProGRP influencing the prognosis of patients.

The study carried out in 2006 by Huang et al confirm the usability of both NSE and ProGRP in evaluating the response to treatment of SCLC patients and the effect of their baseline levels on progression-free survival. However, the authors underline that NSE is a better prognostic factor than ProGRP because unlike ProGRP, NSE is a prognostic factor independent of the stage of disease. ${ }^{69}$

Other resolutions were suggested by Ono et al ${ }^{74}$ confirming the effect of the percent change in the ProGRP concentration before the third cycle of chemotherapy on a 1-year survival. Similarly, Sunaga et al showed a 50\% reduction in the ProGRP concentration after treatment to be a favorable prognostic factor for 2-year survival. ${ }^{50}$ The time of observation is also important in the assessment of the prognosis. The divergences in the course of survival curves, according to the discriminatory value of marker before treatment, are more apparent after $>1$ year of observation..$^{56,65,75}$ Studies conducted in the Oncology Center, Cracow Branch, in both LD-SCLC patients and in groups where the number of patients with LD was predominant (two-thirds of the study group) indicated survival dependence on the initial marker level. ${ }^{76,77}$ In multivariate analysis, taking into account the stage of disease, the PS and the concentration of NSE, ProGRP did not confirm that ProGRP was an independent prognostic factor. ProGRP as an independent prognostic factor has been documented by Nisman et al. These investigators have shown that the relative risk of death for patients with initial ProGRP levels $>140 \mathrm{ng} / \mathrm{L}$ was more than fourfold higher than those with lower marker levels, while the relative risk of death for patients with poorer PS, no response to treatment and advanced stage of disease was 2.5-fold, 1.35-fold and 1.27-fold greater, respectively, when compared to the other patients. However, it should be emphasized that NSE values as a prognostic factor were not analyzed in these studies. ${ }^{58}$ All researchers agree that in evaluation of cancer patients' prognosis, the basic "prognostic factor" is the stage of the disease. While the concentration and frequency of elevated NSE results show a clear dependency on the stage of disease in SCLC patients, for ProGRP, this dependency is weaker. Therefore, in multivariate analysis, during simultaneously evaluating, in addition to clinical parameters, the concentration of both markers, NSE remains an independent predictor for survival.

In SCLC patients, diagnostic utility of other tumor markers, such as CEA and CYFRA 21-1 and in recent years also HE4, was also verified. ${ }^{78}$ Compared to ProGRP $(0.923 \pm 0.03)$, the AUC for HE4 (0.884 \pm 0.03$)$ was lower than that for ProGRP but higher in comparison to NSE $(0.826 \pm 0.04)$, although differences were not statistically significant (Figure 1).

HE4 concentrations, similar to that of NSE and ProGRP concentrations in patients with extensive disease-SCLC, were significantly higher than those with LD-SCLC. In addition, in patients with a worse PS (PS $>1$ ), the HE4 level was higher compared to those with better PS (PS $\leq 1)$. The prognostic value of HE4 has also been confirmed. In addition to the adverse effects on survival of high levels of NSE and ProGRP, also HE4 levels $>150 \mathrm{pmol} / \mathrm{L}$ are associated with worse prognosis of SCLC patients (Figure 2).

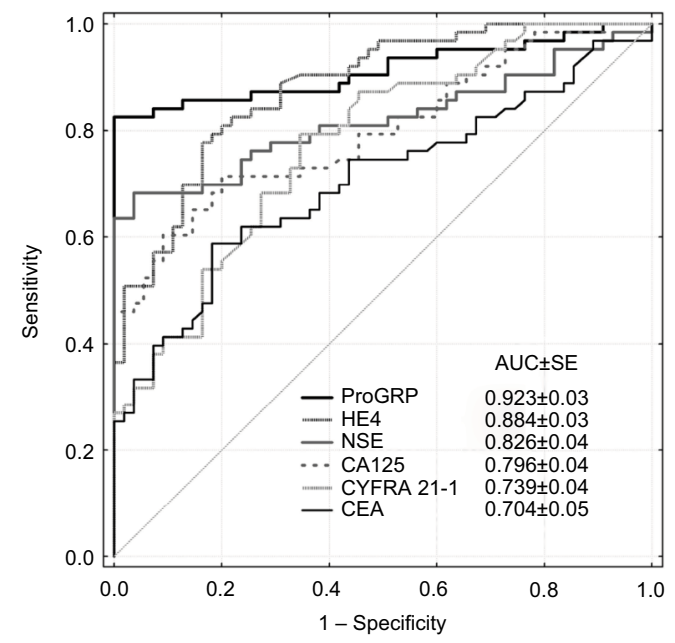

Figure I ROC curve for ProGRP, HE4, NSE, CA 125, CYFRA 2I-I and CEA plotted for SCLC versus reference group.

Note: Copyright (C) 2016. Reproduced from Clinical Laboratory. Wojcik E, Tarapacz J, Rychlik U, et al. Human epididymis protein 4 (HE4) in patients with small-cell lung cancer. Clin Lab. 2016;62(9):1625-1632. ${ }^{79}$

Abbreviations: ROC, receiver operating characteristic; SCLC, small-cell lung cancer; AUC, area under the ROC curve; SE, standard error. 


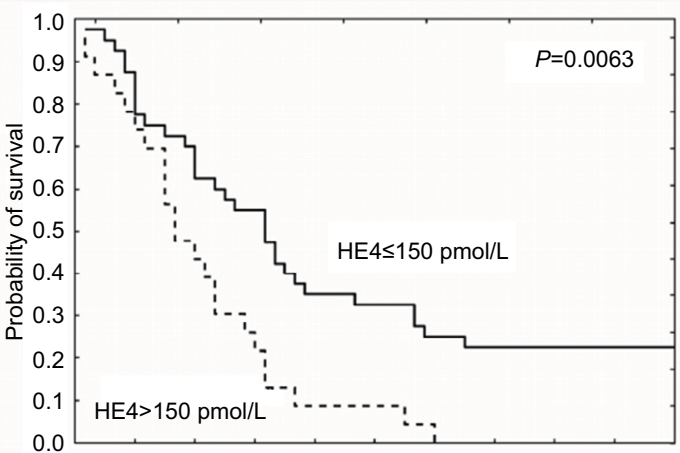

Time (months)

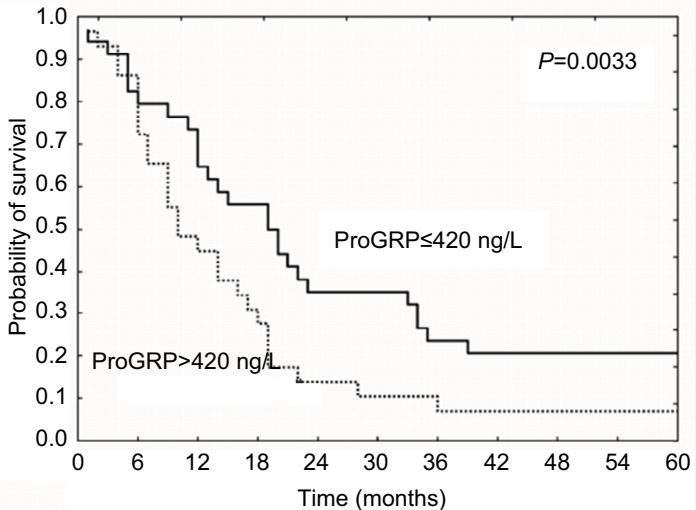

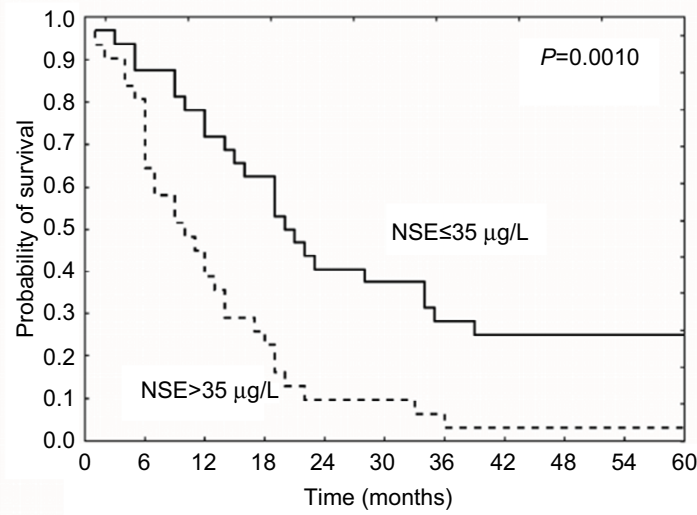

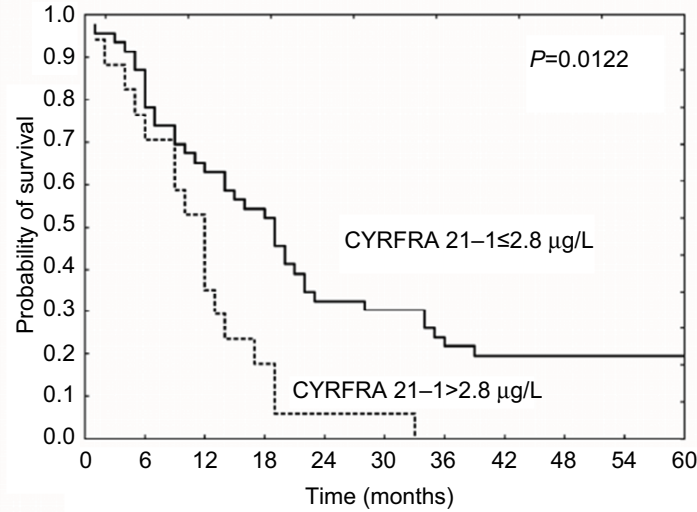

Figure 2 Kaplan-Meier survival curves of 5-year survival based on baseline serum HE4, NSE, ProGRP and CYFRA 2I-I levels.

Note: Copyright @ 2 2016. Reproduced from Clinical Laboratory. Wojcik E, Tarapacz J, Rychlik U, et al. Human epididymis protein 4 (HE4) in patients with small-cell lung cancer. Clin Lab. 2016;62(9):1625-1632. ${ }^{79}$

The clinical parameters and HE4 appeared to be independent prognostic factors when NSE and ProGRP were excluded from multivariate analysis. ${ }^{79}$

A number of studies document the utility of NSE and ProGRP in the diagnosis, monitoring and evaluation of treatment response to SCLC patients, as well as the predictive and prognostic values of these markers.
Certain discrepancies and controversies regarding the usefulness of these markers at various stages of the diagnostic process, as well as in the evaluation of prognosis, justify further investigation. A summary of the information obtained both from literature and from our studies on the utility of ProGRP in diagnosing SCLC patients is contained in Table 2.

Table 2 Basic information about the utility of ProGRP determinations in SCLC

\section{Diagnosis}

I ProGRP - helpful in the assessment of lung cancer histological type - differential diagnostics

2 In SCLC patients, diagnostic sensitivity of ProGRP determination is higher in comparison to NSE at similar diagnostic specificity

3 In LD-SCLC patients during combined chemoradiotherapy, the kinetics of ProGRP concentration drop is more adequate to patients' response to treatment than in the case of NSE

4 Increased concentration of ProGRP before PCl after induction chemotherapy is suggestive of the presence of residual disease 66

5 ProGRP $>46 \mathrm{pg} / \mathrm{mL}$ before $\mathrm{PCl}-12.5$-fold higher risk of cerebral metastases

Increased ProGRP after four chemotherapy cycles in patients with diagnosed CR - indication to application of two more 66 chemotherapy cycles

7 After treatment, patients with CR present lower ProGRP concentration compared to those with SD+PD

9 Before treatment - high ProGRP concentration (140, $410 \mathrm{ng} / \mathrm{L})$ - unfavorable prognostic factor

Abbreviations: SCLC, small-cell lung cancer; LD, limited disease; PCI, prophylactic cranial irradiation; CR, complete remission; SD, stable disease; PD, progression. 
Presumably research ProGRP isoforms as well as a wide of different biomarkers of inflammation can supplement existing information on studies ProGRP utility in the diagnosis of lung cancer.

\section{Disclosure}

The authors report no conflicts of interest in this work.

\section{References}

1. Parkin DM, Bray F, Ferlay J, Pisani P. Global cancer statistics, 2002. CA Cancer J Clin. 2005;55(2):74-108.

2. Torre LA, Bray RF, Siegel RL, Ferlay J, Lortet-Tieulent J, Jemal A. Global cancer statistics, 2012. CA Cancer J Clin. 2015;65(2):87-108.

3. Kalemkerian GP, Akerley W, Bogner P, et al; National Comprehensive Cancer Network. Small cell lung cancer. J Natl Compr Canc Netw. 2013;11(1):78-98.

4. Stupp R, Monnerat C, Turrisi AT, Perry MC, Leyvraz S. Small cell lung cancer: state of the art and future perspectives. Lung Cancer. 2004;45(1):105-117.

5. Micke P, Faldum A, Metz T, et al. Staging small cell lung cancer: Veterans Administration Lung Study Group versus International Association for the Study of Lung Cancer - what limits limited study? Lung Cancer. 2002;37:271-276.

6. Hanna NH, Einhorn LH. Small-cell lung cancer: state of the art. Clin Lung Cancer. 2002;4(2):87-94.

7. Travis WD. Update on small cell carcinoma and its differentiation from squamous cell carcinoma and other non-small cell carcinomas. Mod Pathol. 2012;25:S18-S30.

8. Demeure MJ. Physiology of the APUD system. Semin Surg Oncol. 1993;9(5):362-367.

9. Stieber P, Holdenrieder S. Lung cancer biomarkers - where we are and what we need. Cancer Biomark. 2009-2010;6(3-4):221-224.

10. Modlin IM, Gustafsson BI, Moss SF, Pavel M, Tsolakis AV, Kidd M. Chromogranin A - biological function and clinical utility in neuro endocrine tumor disease. Ann Surg Oncol. 2010;17(9):2427-2443.

11. Lamy PJ, Grenier J, Kramar A, Pujol JL. Pro-gastrin-releasing peptide, neuron specific enolase and chromogranin A as serum markers of small cell lung cancer. Lung Cancer. 2000;29(3):197-203.

12. Korse CM, Taal BG, Vincent A, et al. Choice of tumor markers in patients with neuroendocrine tumors is dependent on the histological grade. A marker study of Chromogranin A, Neuron specific enolase, Progastrin-releasing peptide and cytokeratin fragments. Eur J Cancer. 2012;48(5):662-667.

13. Stridsberg M, Eriksson B, Oberg K, Jansson ET. A comparison between three commercial kits for chromogranin A measurements. J Endocrinol. 2003;177(2):337-341.

14. Isgro MA, Bottoni P, Scatena R. Neuron-specific enolase as a biomarker: biochemical and clinical aspects. Adv Exp Med Biol. 2015;867:125-143.

15. Carney DN, Marangos PJ, Ihde DC, et al. Serum neuron-specific enolase a marker for disease extent and response to therapy of small-cell lung cancer. Lancet. 1982;1:583-585.

16. Pujol JL, Boher JM, Grenier J, Quantin X. CYFRA 21-1, neuron specific enolase and prognosis of non-small cell lung cancer: prospective study in 621 patients. Lung Cancer. 2001;31:221-231.

17. Molina R, Auge JM, Bosch X, et al. Usefulness of serum tumor markers, including Progastrin-releasing peptide, in patients with lung cancer: correlation with histology. Tumour Biol. 2009;30:121-129.

18. Huang L, Zhou JG, Yao WX, et al. Systemic review and meta-analysis of the efficacy of serum neuron-specific enolase for early small cell lung cancer screening. Oncotarget. 2017;8:64358-64372.

19. Zhou M, Wang Z, Yao Y, Zhou H, Liu M, Sun J. Neuron-specific enolase and response to initial therapy are important prognostic factors in patients with small cell lung cancer. Clin Trans Incol. 2017;19:865-873.
20. Drivsholm L, Osterlind K, Cooper EH, Purves DA. Neuron-specific enolase (NSE) in serum. Comparison of monoclonal versus polyclonal assay based on 392 blood samples. Int J Biol Markers. 1995;10(1): $1-4$.

21. Stern P, Bartos V, Uhrova J, et al. Performance characteristics of seven neuron-specific enolase assays. Tumour Biol. 2007;28(2):84-92.

22. McDonald TJ, Nilsson G, Vagne M, Ghatei M, Bloom SR, Mutt V. A gastrin releasing peptide from porcine non-antral gastric tissue. Gut. 1978;19(9):767-774.

23. Yamaguchi K, Abe K, Kameya T, et al. Production and molecular size heterogeneity of immunoreactive gastrin-releasing peptide in fetal and adult lungs and primary lung tumors. Cancer Res. 1983;43(8):3932-3939.

24. Toi-Scott M, Jones C, Kane M. Clinical correlates of bombesin-like peptide receptor subtype expression in human lung cancer cells. Lung Cancer. 1996;15(3):341-354.

25. Dumesny C, Patel O, Lachal S, Girand AS, Baldwin GS, Shalkes A. Synthesis, expression and biological activity of the prohormone for gastrin releasing peptide (ProGRP). Endocrinology. 2006;147(1):502-509.

26. Patel O, Shulkes A, Baldwin GS. Gastrin-releasing peptide and cancer. Biochim Biophys Acta. 2006;1766(1):23-41.

27. Sciarra A, Mariotti G, Voria G, Pastore A, Monti S, Di Silverio F. Neuroendocrine differentiation in human prostate tissue: is it detectable and treatable? BJU Int. 2003;91(5):1464-4096.

28. Castro MP, McDonald TJ, Qualman SJ, Odorisio TM. Cerebrospinal fluid gastrin releasing peptide in the diagnosis of leptomeningeal metastatses from small cell carcinoma. Cancer. 2001;91(11):2122-2126.

29. Van de Wiele C, Dumont F, Dierckx RA, et al. Biodistribution and dosimetry of Tc-RP527, a gastrin-releasing peptide (GRP) agonist for the visualization of GRP receptor-expressing malignancies. J Nucl Med. 2001;42(11):1722-1727.

30. Cuttitta F, Federko J, Gu J, Lebacq-Verheyden AM, Linnoila I, Battey JF. Gastrin-releasing peptide gene-associated peptides are expressed in normal human fetal lung and small cell lung cancer: a novel peptide family found in man. J Clin Endocrinol Metab. 1988;67(3): 576-583.

31. Aoyaki K, Miyake Y, Urakami K, et al. Enzyme immunoassay of immunoreactive Pro-gastrin-releasing peptide (31-98) as tumor marker for small cell lung carcinoma: development and evaluation. Clin Chem. 1995;41(4):537-543.

32. Miyake Y, Kodama T, Yamaguchi K. Pro-gastrin-releasing peptide (31$98)$ is a specific tumor marker in patients with small cell lung carcinoma. Cancer Res. 1994;54(8):2136-2140.

33. Patel O, Dumensy C, Shulkes A, Baldwin GS. Recombinant C-terminal fragments of the gastrin-releasing peptide precursor are bioactive. Cancer Lett. 2007;254(1):87-83.

34. Adachi N, Aoyagi K, Saito M, Matsuda I, Yamaguchi K. Age-related changes of serum progastrin-releasing peptide levels during childhood. Acta Paediatr Jpn. 1997;39(3):336-339.

35. Molina R, Auge JM, Alicarte J, Fillela X, Vinolas N, Ballesta AM. Pro-gastrin-releasing peptide in patients with benign and malignant diseases. Tumour Biol. 2004;25:56-61.

36. Korse CM, Holderieder S, Zhi XY, et al. Multicenter evaluation of a new progastrin-releasing peptide (ProGRP) immunoassay across Europe and China. Clin Chim Acta. 2015;438:388-395.

37. Bubanovic G, Pavicevic R, Franjevic A. Determining the cut-off value of Pro-Gastrin Releasing Peptide (ProGRP) in lung cancer according to population characteristics. Coll Antropol. 2008;32(4):1155-1164.

38. Willey JC, Lechner JF, Harris CC. Bombesin and the C-terminal tetradecapeptide of gastrin-releasing peptide are growth factors for normal human epithelial cells. Exp Cell Res. 1984;153(1):245-248.

39. Norlund MS, Bjener J, Warren DJ, Nustad K, Paus E. Progastrin -releasing peptide: stability in plasma/serum and upper limit. Tumour Biol. 2008;29(3):204-210.

40. Granberg D, Skogseid B, Welin S, Orlefors H, Oberg K, Wilander E. Gastrin releasing peptide in neuroendocrine tumours. Acta Oncol. 2006;45(1):23-27. 
41. Parra-Robert M, Orois A, Auge JM, Halperin I, Filella X, Molina R. Utility of proGRP as a tumor marker in the medullary thyroid carcinoma. Clin Chem Lab Med. 2017;55(3):441-446.

42. Yamaguchi K, Katagiri H, Takahashi M, et al. ProGRP is a possible marker for patients with Ewing sarcoma. Biomed Res. 2015;36(4): 275-277.

43. Lee JE, Lee JH, Hong M, et al. Instability of plasma and serum Progastrin releasing peptide during repeated freezing and thawing. Osong Public Health Res Perspect. 2016;7(6):351-355.

44. Kulpa J, Wojcik E, Sobolewska K, Stasik Z. NSE and ProGRP in serum and plasma. ISOBM 2009; [abstracts book] 38.

45. Yoshimura T, Fujita K, Kawakami S, et al. Stability of Pro-gastrinreleasing peptide in serum versus plasma. Tumour Biol. 2008;29: 224-230.

46. Takada M, Kusunoki Y, Masuda N, et al. Pro-gastrin-releasing peptide (31-98) as a tumor marker of small cell lung cancer comparative evaluation with neuron-specific enolase. Br J Cancer. 1996;73(10):1227-1232.

47. Stieber P, Dienemann H, Schalhorn A, et al. Pro-gastrin-releasing peptide (ProGRP) - a useful marker in small cell lung carcinomas. Anticancer Res. 1999;19(4A):2673-2678.

48. Stieber P, Aronsson AC, Bialk P, et al. Tumor markers in lung cancer: EGTM recommendations. Anticancer Res. 1999;19:2785-2820.

49. Fizazi K, Cojean I, Pignon JP, et al. Normal serum neuron specific enolase (NSE) value after first cycle of chemotherapy. Cancer. 1998;82(6):1049-1055.

50. Sunaga N, Tsuchiya S, Minato K, et al. Serum Pro-gastrin-releasing peptide is a useful marker for treatment monitoring and survival in small cell lung cancer. Oncology. 1999;57(2):143-148.

51. Schneider J, Philipp M, Salewski L, Velcovsky H-G. Pro-gastrinreleasing peptide (ProGRP) and neuron specific enolase (NSE) in therapy control of patients with small cell lung cancer. Clin Lab. 2003;49(1-2):35-42.

52. Jorgensen LGM, Osterlind K, Genolla J, et al. Serum neuron-specific enolase (S-NSE) and the prognosis in small-cell lung cancer (SCLC): a combined multivariable analysis on data from nine centers. Br J Cancer. 1996;74(3):463-467.

53. Bremnes RM, Sundstrom S, AAsebo U, Kaasa S, Hatlevoll R, Aamdal $\mathrm{S}$. The value of the prognostic factors in small cell lung cancer: results from a randomized multicenter study with minimum 5-years follow-up. Lung Cancer. 2003;39(3):303-313.

54. Pujol JL, Quantin X, Jacot W, Boher JM, Grenier J, Lamy PJ. Neuroendocrine and cytokeratin serum markers as prognostic determinants of small cell lung cancer. Lung Cancer. 2003;39(2):131-138.

55. Niho S, Nishiwaki Y, Goto K, et al. Significance of serum pro-gastrinreleasing peptide as a predictor of relapse of small cell lung cancer: comparative evaluation with neuron specific enolase and carcinoembryonic antigen. Lung Cancer. 2000;27(3):159-167.

56. Nisman B, Biran H, Ramu N, Heching N, Barak V, Peretz T. The diagnostic and prognostic value of ProGRP in lung cancer. Anticancer Res. 2009;29(11):4827-4832.

57. Liu L, Teng J, Zhang L, et al. The combination of the tumor markers suggests the histological diagnosis of lung cancer. Biomed Res Int. 2017;2017:9

58. Nisman B, Nechustan H, Biran H, et al. New Architect plasma progastrin-releasing peptide assay for diagnosing and monitoring small-cell lung cancer. Br J Cancer. 2016;114(4):469-476.

59. Tang JH, Zhang XL, Zhang ZH, et al. Diagnostic value of tumor marker progastrin-releasing peptide in patients with small cell lung cancer: a systemic review. Chin Med J. 2011;124(10):1563-1568.

60. Yang $\mathrm{HJ}, \mathrm{Gu}$ Y, Chen $\mathrm{CH}, \mathrm{Xu} \mathrm{C}$, Bao YX. Diagnostic value of progastrin-releasing peptide for small cell lung cancer: a meta-analysis. Clin Chem Lab Med. 2011;49(6):1039-1046.
61. Wang H, Qian J. Serum pro-gastrin-releasing peptide in diagnosis of small cell lung cancer: a meta analysis. J Can Res Ther. 2016;12(suppl): C260-C263.

62. Glas AS, Lijmer JG, Prins MH, Bonsel GJ, Bossuyt MM. The diagnostic odds ratio: a single indicator of test performance. J Clin Epidemiol. 2003;56:1129-1135.

63. Lv SP, Wang Y, Huang L, Wang F, Zhou JG, Ma H. Meta-analysis of serum gastrin-releasing peptide precursor as a biomarker for diagnosis of small cell lung cancer. Asian Pac J Cancer Prev. 2017;18(2):391-397.

64. Wojcik E, Kulpa J, Sas-Korczynska B. ProGRP and NSE for follow-up of small cell lung cancer patients with limited disease. J Thorac Oncol. 2007;2(8):S514

65. Wojcik E, Kulpa JK, Sas-Korczyńska B, Korzeniowski S, Jakubowicz J. ProGRP and NSE in therapy monitoring in patients with small cell lung cancer. Anticancer Res. 2008;28(5B):3027-3034.

66. Yonemori K, Sumi M, Fujimoto N, et al. Pro-gastrin-releasing peptide as a factor predicting the incidence of brain metastases in patients with small cell lung carcinoma with limited disease receiving prophylactic cranial irradiation. Cancer. 2005;104(4):811-816.

67. Holdenrieder S, von Pawel J, Dankelmann E, et al. Nucleosomes, ProGRP, NSE, CYFRA 21-1, and CEA in monitoring first-line chemotherapy of small cell lung cancer. Clin Cancer Res. 2008;14(23):7813-7821.

68. Oh HJ, Park HY, Kim KH, et al. Progastrin-releasing peptide as a diagnostic and therapeutic biomarker of small cell lung cancer. J Thorac Dis. 2016;8(9):2530-2537.

69. Huang Z, Xu D, Zhang F, Song L. Pro-gastrin-releasing peptide and neuron-specific enolase: useful predictors of response to chemotherapy and survival in patients with small cell lung cancer. Clin Transl Oncol. 2016;18(10):1019-1025.

70. Hirose T, Okuda K, Yamaoka T, et al. Are levels of pro-gastrin-releasing peptide or neuron-specific enolase at relapse prognostic factors after relapse in patients with small-cell lung cancer? Lung Cancer. 2011;71(2):224-228.

71. Eisenhauer EA, Therrasse P, Bogaerts J, et al. New evaluate the response evaluation criteria in solid tumours: revised RECIST guideline (version1.1). Eur J Cancer. 2009;45:228-247.

72. Stieber P, Holdenrieder S. Lung cancer biomarkers - Where we are and what we need. Cancer Biomark. 2010;6(3-4):221-224.

73. Petrovic M, Bukumiric Z, Zdravkovic V, Mitrovic S, Atkinson HD, Jurisic $\mathrm{V}$. The prognostic significance of the circulating neuroendocrine markers chromogranin A, pro-gastrin-releasing peptide, and neuronspecific enolase in patients with small-cell lung cancer. Med Oncol. 2014;31(2):823.

74. Ono A, Naito T, Ito I, et al. Correlations between serial pro-gastrinreleasing peptide and neuron-specific enolase levels, and the radiological response to treatment and survival of patients with small-cell lung cancer. Lung Cancer. 2012;76(3):439-444.

75. Shibayama T, Ueoka H, Nishii K, et al. Complementary roles of progastrin-releasing peptide (ProGRP) and neuron specific enolase (NSE) in diagnosis and prognosis of small cell lung cancer (SCLC). Lung Cancer. 2001;32(1):61-69.

76. Wojcik E, Jakubowicz J, Skotnicki P, Sas-Korczyńska B, Kulpa JJ. IL-6 and VEGF in small cell lung cancer patients. Anticancer Res. 2010;30:1773-1778.

77. Wojcik E, Stasik Z, Sas-Korczyńska B, Rychlik U, Tarapacz J, Kulpa J. Wartość prognostyczna wskaźnika PNI u chorych na drobnokomórkowego raka płuca. Diag Lab. 2013;49(4):369-375. Polish.

78. Wang X, Fan Y, Wang J, Wang H, Liu W. Evaluating the expression and diagnostic value of human epididymis protein 4 (HE4) in small cell lung cancer. Tumour Biol. 2014;35(7):6847-6853.

79. Wojcik E, Tarapacz J, Rychlik U, et al. Human epididymis protein 4 (HE4) in patients with small-cell lung cancer. Clin Lab. 2016;62(9): 1625-1632. 


\section{Publish your work in this journal}

Lung Cancer: Targets and Therapy is an international, peer-reviewed, open access journal focusing on lung cancer research, identification of therapeutic targets and the optimal use of preventative and integrated treatment interventions to achieve improved outcomes, enhanced survival and quality of life for the cancer patient. Specific topics covered in the journal include: Epidemiology, detection and screening; Cellular research and biomarkers; Identification of biotargets and agents with novel published authors.

mechanisms of action; Optimal clinical use of existing anticancer agents, including combination therapies; Radiation and surgery; Palliative care; Patient adherence, quality of life, satisfaction; Health economic evaluations. The manuscript management system is completely online and includes a very quick and fair peer-review system. Visit http://www.dovepress.com/testimonials.php to read real quotes from

Submit your manuscript here: https://www.dovepress.com/lung-cancer-targets--therapy-journal 